\title{
Hematological Effects and Benchmark Doses of Long-Term Co-Exposure to Benzene, Toluene, and Xylenes (BTX) in BTX-Exposed Petrochemical Workers Cohort (BEPWC)
}

\section{Zhaorui Zhang \\ Sun Yat-Sen University \\ Xin Liu \\ Sun Yat-Sen University \\ Xinjie Zhang \\ Sun Yat-Sen University \\ Yingying Zhang \\ Sun Yat-Sen University}

\section{$\mathrm{Na}$ Deng}

Sun Yat-Sen University

\section{Guanchao Lai}

Guangdong Province Hostital for Occupational Disease Prevension and Treatment

\section{Aichu Yang}

Guangdong Province Hospital for Occupational Disease Prevention and Treatment

\section{Yongshun Huang}

Guangdong Province Hospital for Occupational Disease Prevention and Treatment

\section{Shanfeng Dang}

Occupational Disease Prevention and Treatment Institute of Sinopec Maoming Perochemical Company

\section{Yanqun Zhu}

Occupational Disease Prevention and Treatment Institute of Sinopec Maoming Petrochemical Company

Xiumei Xing

Sun Yat-Sen University

\section{Yongmei Xiao}

Sun Yat-Sen University

Qifei Deng ( $\square$ dengqf3@mail.sysu.edu.cn )

Sun Yat-Sen University https://orcid.org/0000-0002-7554-0402

\section{Research Article}


Keywords: BTX components, long-term occupational co-exposure, hematological effects, benchmark dose, BTX-Exposed Petrochemical Workers Cohort

Posted Date: January 12th, 2022

DOI: https://doi.org/10.21203/rs.3.rs-1200872/v1

License: (c) (1) This work is licensed under a Creative Commons Attribution 4.0 International License. Read Full License 


\section{Abstract \\ Background}

Ubiquitous benzene, toluene, and xylenes (BTX) frequently occur together. Exposure to single BTX component and BTX-rich mixtures could induce hematological effects. However, it still needs to clarify the hematological influences of long-term co-exposure to BTX components, and propose reference exposure levels (REL) base on their hematological effects.

\section{Objective}

We sought to evaluate the hematological effects of long-term BTX co-exposure and estimate REL based on these effects.

\section{Methods}

We established BTX-Exposed Petrochemical Workers Cohort (BEPWC), quantified long-term BTX exposure levels by calculating cumulative exposure doses (CED), and detected multiple hematologic parameters in both baseline and follow-up stages. Generalized weighted quantile sum (gWQS) regression models were used to evaluate the combined effects of BTX components and identify their contributions. Benchmark Dose (BMD) Software was used to calculate BMD and the lower confidence limits (BMDL).

\section{Results}

Most hematologic parameters were decreased after four-year follow-up $(P<0.05)$. We found a positive association of benzene with the decline in monocyte counts $(\beta=0.012)$, and a negative association of toluene with the decline in mean corpuscular hemoglobin concentrations $(\beta=-0.905)$ after false discovery rate (FDR) adjustment. The associations of BTX components with the decline in hematologic parameters were mostly significantly stronger in subjects with higher baseline parameters, males, drinkers, and overweighted subjects (FDR-adjusted $P_{\text {interaction }}<0.05$ ). BTX components had positive combined effects on the decline in monocyte counts, red blood cell counts, and hemoglobin concentrations ( $P_{\text {trend }}$ for WQS index <0.05). BMD (and BMDL) for CED levels of benzene, toluene, and xylene were estimated at 2.138 (1.559), 1.449 (1.325), and 2.937 (2.312) mg/m³xyear, respectively.

\section{Conclusions}

Our study revealed complex hematological effects of long-term BTX occupational co-exposure, and proposed some REL-TWA around $0.01 \mathrm{ppm}$ for BTX components based on their hematological effects. All these findings are worthy of further investigation. 


\section{Introduction}

Benzene, toluene, and xylenes (BTX) are representative single-ring aromatic compounds. They ubiquitously distribute and frequently co-exist in various human environments due to their high volatility and extensive emission sources. The most important culprits of environmental contamination and human exposure are man-made sources like vehicle exhaust, cigarette smoke, and the manufacture and usage of BTX compounds and their related products (including petroleum products, pharmaceutical products, and common consumer goods, such as adhesives, paints, rubber products, and solvents) (Bolden et al. 2015). With the accelerating development of industrialization, many developing countries, including China, have achieved great growth in the production of petrochemical products, which makes petrochemical industrial activities to be one of the major BTX sources and makes petrochemical workers long-termly exposed to relative higher abundant of BTX components (Cetin et al. 2003).

Highly volatile BTX components can be readily absorbed following inhalation exposure, extensively metabolized by cytochrome P450 enzymes (CYPs), and distribute to lipid-rich and highly vascular tissues (such as bone marrow) due to their lipophilicity (Davidson et al. 2020). In addition to their common physicochemical characteristics and metabolic processes, BTX compounds can also cause some similar adverse health effects with chronic exposure (Davidson et al. 2020). For instance, the most prominent and severe health effects resulting from chronic benzene exposure are hematological effects characterized by depressed numbers of circulating blood cell types, aplastic anemia, and leukemia (Davidson et al. 2020; Zhang et al. 2020). The International Agency for Research on Cancer (IARC) has classified benzene as a Group 1 carcinogen (Davidson et al. 2020). Although human evidence regarding the hematotoxicity of toluene and xylenes are not as solid as those of benzene, their influences on hematologic parameters have recently drawn more and more attentions (Cakmak et al. 2020; Chen et al. 2019; Doherty et al. 2017). However, the epidemiological evidence of hematological effects induced by individual BTX component are not quite conclusive, probably because of the confounding effects of coexposure to other BTX components (ATSDR 2004).

Multiple pollutants often co-exist in human environments, which may induce deleterious health effects in an additive, synergistic, or antagonistic manner (ATSDR 2004; Deng et al. 2019). Increasing studies have indicated that the toxic behaviors of individual BTX component can be modified by other co-existed BTX components due to their competitive metabolic interactions (ATSDR 2004). For example, benzene-related adverse effects can be modified by the capacity of toluene (ATSDR 2004; Robert Schnatter et al. 2010). Several epidemiologic studies have been located that directly examined the hematological responses to BTX-rich mixtures (Chen et al. 2019; Doherty et al. 2017; Samadi et al. 2019). However, the combined hematological effects of BTX components and their respective contributions still need to be clarified in a relatively larger population.

With increasing awareness of the harm of BTX components, many countries have established or recommended various regulatory or advisory environmental and occupational exposure limits, and applied multiple countermeasures to reduce BTX (especially benzene) concentrations below these limits 
in human environments as much as possible. However, significant hematological changes have still been observed in individuals chronically exposed to benzene at concentrations lower than $1 \mathrm{ppm}$ which is the strictest and commonly-applied regulatory occupational exposure limit (Koh et al. 2015; Lan et al. 2004; Qu et al. 2002). Koh et al. (2015) conducted a large-scale study among Korean workers, and observed some negative associations of benzene with the counts of red blood cell (RBC) and lymphocytes in workers who were exposed to concentrations of 0.01-0.1 ppm. Moreover, the existing regulatory or advisory exposure limits for toluene and xylene are established mainly based on their non-hematological health effects. For instance, U.S. Environmental Protection Agency (EPA) has established Reference Concentrations (RfC) of $5 \mathrm{mg} / \mathrm{m}^{3}$ for toluene based on its neurological effects in humans (EPA 2005), and Agency for Toxic Substances and Disease Registry (ATSDR) has calculated a chronic inhalation minimal risk level (MRL) of $0.4 \mathrm{mg} / \mathrm{m}^{3}$ (about $0.1 \mathrm{ppm}$ ) for xylene based on its neurological effects in occupationally exposed workers (ATSDR 2007a). Thus, it is an important task to propose a more sensitive reference exposure level (REL) for benzene, and to fill the research gap of REL for toluene and xylene based on their hematological effects in humans, especially in occupational-exposed populations which are at a much higher risk of hematological damages. Prior to the 1990's, REL were mainly determined from no-observed-adverse-effect levels (NOAEL) or lowest-observed-adverse-effect levels (LOAEL). Recently, Benchmark doses (BMD) approach is highly recommended as it incorporates and conveys more information than NOAEL or LOAEL (EPA 2012). BMD are the dose levels corresponding to a predetermined benchmark response (BMR), such as a $10 \%$ increase in health damage incidence. BMD approach derives dose-response curves by fitting mathematical models to all collected data to obtain BMD and its statistical lower confidence limit (BMDL).

Considering longitudinal studies in occupational population are beneficial to fully understand the health effects of long-term BTX co-exposure and then propose some REL based on their health effects, we had established a cohort, named as BTX-Exposed Petrochemical workers Cohort (BEPWC), in petrochemical workers who had been long-termly working in occupational environments with the co-existence of BTX components. We quantified their BTX occupational exposure levels by calculating cumulative exposure doses (CED) based on their work years and the long-term mean 8-hour time-weighted average (8h-TWA) concentrations in workplaces. So far, we had completed the baseline survey and the first follow-up survey, and had measured some health indicators, including hematologic parameters, in baseline and follow-up stage. In the present study, we first calculated the decline for multiple hematologic parameters by the parameters measured in baseline stage minus their corresponding values measured in follow-up stage. Then we evaluated the associations of BTX components with the decline in hematologic parameters, and assessed the effect modification of baseline parameters and general characteristics on these associations. We also evaluated the combined hematological effects of BTX exposure on the decline in hematologic parameters. Finally, we estimated the BMD and BMDL for each BTX component based on hematological effects in BEPWC panel.

\section{Materials And Methods}




\subsection{BEPWC establishment}

In order to explore the health effects attributed to long-term BTX occupational co-exposure, we established BEPWC panel in two large-scale state-run petrochemical companies located in Guangzhou and Maoming in Guangdong Province, China, during 2011-2012. As the co-existence of other occupational hazards, such as noise and other chemical toxicants, could also damage workers' health, we annually invited professional occupational health assessment agencies to systematically evaluate the primary hazards in all workplaces for three years before BEPWC started. Based on the manufacturing technique and the occupational environment monitoring data, the agencies had identified 32 workplaces in two petrochemical companies where BTX compounds were always the primary occupational hazards, such as petroleum refining, chemical production, and petroleum processing. One of these workplaces were newly constructed in 2009.

In BEPWC baseline stage, we selected our participants from all workers who were working in those workplaces based on a serial of inclusion and exclusion criteria: a) We included workers who had been employed in those workplaces for one year or more; b) We excluded workers with any types of selfreported and/or diagnosed carcinomas, serious cardiopulmonary diseases, hematological diseases, chronic immune diseases and inflammation, and/or diabetes; c) We excluded workers taking medicine or experiencing X-ray examination in one week preceding the baseline survey; d) We excluded workers with any obviously abnormities in baseline physical examination (including hematologic parameters); and e) we excluded workers who were unwilling or unable to complete any parts of survey (including completing occupational questionnaire, participating in physical examinations, and providing enough biological materials). Eventually, we enrolled 1443 workers in BEPWC panel in the baseline stage, and planned to follow up these participants every 4 5 years. Our prospective cohort study was approved by the Ethical Review Committee of School of Public Health, Sun Yat-sen University.

In the first follow-up survey, 11 BEPWC workers were unwilling or unable to complete any part of survey for personal or business reasons; 3 had developed serious diseases; and 5 had took medicine and/or done X-ray examination in one weeks preceding the survey. We had collected the detailed reasons for the latter 8 workers with health situations and considered that their health situations were unlikely to be related with BTX exposure but might influence the health status in the follow-up stage. Thus, we decided to exclude these workers from the first follow-up study. Eventually, 1424 participants had been successfully followed up (follow-up rate: 98.68\%). Among the total population of BEPWC cohort, 1054 subjects had provided enough EDTA-anticoagulated blood samples in both stage for hematologic parameter detection (Table S1). Thus, they were included in the present study.

\subsection{Collection of general information and biological samples}

In the baseline stage and the follow-up survey, each participant signed a written informed consent form and then was interviewed face-to-face by trained personnel. A pretested occupational questionnaire was 
used to collect general information, including demographic characteristics, lifestyle (such as smoking and drinking status), medical history and medication use, and occupational experiences (such as workplaces and work years). Smokers were defined when individuals had smoked more than 1 cigarette per day for $\geq 1$ year in their lifetime, and their pack-years of smoking were calculated by multiplying average packs of cigarettes smoked per day by the duration of smoking. Drinkers were defined if they had drunk alcohol beverages more than once a week for $\geq 1$ year in their lifetime. After the interview, some voluntary subjects donated EDTA-anticoagulated fasting venous blood, heparin-anticoagulated fasting venous blood, and/or morning urine (Table S1). EDTA-anticoagulated blood samples were used for hematologic parameter detection, blood biochemical parameter detection, and/or DNA extraction. Heparin-anticoagulated blood samples were used for comet assay and/or cytokinesis-block micronucleus assay. Urine samples were used for detection of urinary routine parameters, S-phenylmercapturic acid (SPMA), and/or 8-hydroxy-deoxyguanosine (Table S1).

\subsection{Assessment of individual BTX exposure levels}

We seasonally monitored the ambient BTX concentrations in the workplaces of our BEPWC participants for three years preceding the baseline stage (except for the newly constructed workplace which had only been seasonally monitored for 1.5 years after its normal operations) (Table S2). We set up sampling points in each workplace strictly according to "Sampling Specification for Monitoring of Hazardous Substances in the Air of the Workplace" (GBZ 159-2004) (Table S2). We used air samplers (Sp1500, TSI Corporation) and active carbon tubes to collect duplicate air samples at the breathing level (about 1.5 meters from the ground) of each sampling site, with the flow rate at $50 \mathrm{~mL} / \mathrm{min}$ for $2 \sim 8$ hours. We then used thermal desorption and capillary gas chromatography coupled with hydrogen flame ionization detector (Agilent 6890, US) to determine the BTX concentrations, in accordance with the processes and quality control steps recommended by National Institute for Occupational Safety and Health (NIOSH) method 1501. The limits of detection (LOD) for ambient concentrations of benzene, toluene, and xylene were $0.01 \mathrm{mg} / \mathrm{m}^{3}, 0.02 \mathrm{mg} / \mathrm{m}^{3}$, and $0.02 \mathrm{mg} / \mathrm{m}^{3}$, respectively, and the default values below the LOD were replaced by LOD/2 (Table S2). Then we calculated 8h-TWA concentrations. In order to evaluate the longterm occupational BTX exposure levels for all BEPWC participants, we calculated individual BTX CED levels $\left(\mathrm{mg} / \mathrm{m}^{3}\right.$ xyear) by multiplying their work years with the three-year mean 8h-TWA concentrations in their workplaces.

Furthermore, we also conducted a small substudy to evaluate the correlation of this CED assessment method (represented by benzene CED levels) with commonly-used biological monitoring methods (represented by SPMA, a widely-used benzene internal exposure biomarker) (Tuakuila 2013). We selected 941 BEPWC participants who donated enough urinary samples in the baseline stage. We used liquid chromatography/electrospray tandem mass spectrometry to detect urinary SMPA concentrations (Zhang et al. 2020). The LOD for urinary SPMA was $0.01 \mu \mathrm{g} / \mathrm{L}$ and the concentrations of samples with levels below LOD were replaced by $0.005 \mu \mathrm{g} / \mathrm{L}$. SPMA concentrations were standardized by urinary creatinine and expressed as $\mu \mathrm{g} / \mathrm{g}$ creatinine.

\subsection{Detection of hematologic parameters}


Three categories of hematologic parameters were detected in the present study, including leukocyte differential counts [including the counts of white blood cells (WBC, $\left.\times 10^{9} / \mathrm{L}\right)$, neutrophils $\left(\times 10^{9} / \mathrm{L}\right)$, monocytes $\left(\times 10^{9} / \mathrm{L}\right)$, and lymphocytes $\left(\times 10^{9} / \mathrm{L}\right)$ ], RBC indices [including RBC counts $\left(\times 10^{12} / \mathrm{L}\right)$, hemoglobin concentrations $(\mathrm{g} / \mathrm{L})$, hematocrit $(\%)$, mean corpuscular volume $(\mathrm{MCV}, \mathrm{fL})$, mean corpuscular hemoglobin concentration ( $\mathrm{MCHC}, \mathrm{g} / \mathrm{L})$, and mean corpuscular hemoglobin $(\mathrm{MCH}, \mathrm{pg})]$, and platelet indices [platelet counts $\left(\times 10^{9} / \mathrm{L}\right)$, mean platelet volume (MPV, $\mathrm{fL}$ ), platelet distribution width (PDW, \%), and plateletcrit (\%)].

Within two hours of blood sample collection, we send blood samples to a professional clinical laboratory for detection of hematologic parameters by an automatic hematology analyzer (Sysmex XE-2100, Japan). In every year, this laboratory had participated the external quality assessments organized by Guangdong Center for Clinical Laboratory and National Center for Clinical Laboratories in China, respectively. At regular intervals, this laboratory had also conducted calibration and internal quality control according to the "Guideline for the calibration of blood cell assays" (WS/T 347-2011) and the "Analytical quality specifications for routine tests in clinical hematology" (WS/T 406-2012). In every day before sample detection, physicians with specific qualifications followed the standard operating procedures of the automatic hematology analyzer to detect a quality control sample. The blood samples could be detected only if the measured values of quality control samples were in the range of mean $\pm 2 \times$ standard deviation (SD). Furthermore, each blood sample was assayed in duplicate, and the average values were used for all statistical analyses. The intra-assay coefficients of variation for hematologic parameters were all lower than $10 \%$.

\subsection{Evaluation of hematological changes and damages}

As the fluctuations in health-related indicators are associated with a higher risk of adverse health outcome (Kim et al. 2018), we calculated the decline for all hematologic parameters by the levels measured in baseline stage minus the corresponding levels measured in the follow-up stage. To facilitate the BMD calculation, we selected night hematologic parameters which have clinical relevance to chronic exposure to toxic chemicals and bone marrow problems as the parameters of primary interest, including blood cell counts, hemoglobin concentrations, hematocrit, and MPV (Table S3). Furthermore, in order to increase the specificity and reduce the false positive rate, only the subjects with at least two parameters at "abnormally" lower levels in the follow-up stage and/or with "abnormal" decline were classified as the cases of hematological damage. Thus, we defined the cases of hematological damages as those subjects who met at least one of the following criteria: (1) at least 2 out of the selected hematologic parameters (except for MPV which has no related national standards) in follow-up stage were below the lower limits of the corresponding normal range in Chinese adults (Table S3); and (2) the magnitude of the decline in at least 2 out of the selected hematologic parameters were higher than the upper $5 \%$ percentile in population of the same sex.

\subsection{Statistical analysis}


The principal interest of the study was to assess the longitudinal relationship between long-term exposure to BTX components and the decline in hematologic parameters. BTX CED levels were natural logarithm (In) transformed to approximate normal distribution. We considered several baseline characteristics as covariates, including age (continuous), sex (male/female), factory location (Guangzhou/Maoming), body mass index (BMI, continuous), smoking status (smokers/nonsmokers), pack-years of smoking (continuous), drinking status (drinkers/nondrinkers), and the corresponding baseline parameters (continuous). We included these covariates in our statistical analyses unless otherwise specified.

We first evaluated the correlations of average 8h-TWA concentrations of BTX components, and then compared their inter-year differences by generalized estimating equation models. In the correlation substudy of benzene CED levels and urinary SPMA concentrations, we divided 941 participants into four exposure subgroups based on the quartiles of benzene CED levels, and then evaluated the association between benzene CED levels and SPMA concentrations by covariate-adjusted linear regression models. Differences of hematologic parameters between baseline stage and follow-up stage were compared using paired Student $t$ tests. We also compared the magnitude of decline in hematologic parameters between subjects with different general characteristics, including age ( $\leq 40$ vs. $>40$, stratified by the median age), sex (female vs. male), smoking status (nonsmokers vs. smokers), drinking status (nondrinkers vs. drinkers), and BMI ( $<24 \mathrm{~kg} / \mathrm{m}^{2}$ vs. $\geq 24 \mathrm{~kg} / \mathrm{m}^{2}$, stratified by the widely-used overweight standard in Chinese adults). The between-group differences were analyzed by multivariable covariance analysis with adjustment for other covariates.

We evaluated the associations of BTX components with the decline of hematologic parameters in the total population by covariate-adjusted linear regression models to reveal whether the magnitude of decline was increased or decrease with the increase of BTX CED levels. After deriving $P_{\text {trend }}$ value for each association, we calculated the corresponding false discovery rate (FDR)-adjusted $P_{\text {trend }}$ with an available spreadsheet software to adjust for multiple testing (Pike, 2011). Then, we divided the total population to three tertile (low, medium, and high) groups according to the cut-off of 33rd percentile and 67th percentile of the baseline levels of hematologic parameters, and assessed the associations of BTX components with the decline in parameters in subjects with different baseline levels by covariate-adjusted linear regression models. We also performed stratification analysis according to the general characteristics, including age ( $\leq 40$ vs. $>40$ ), sex (female vs. male), smoking status (nonsmokers vs. smokers), drinking status (nondrinkers vs. drinkers), and BMI ( $<24 \mathrm{~kg} / \mathrm{m}^{2} \mathrm{vs}$. $\left.\geq 24 \mathrm{~kg} / \mathrm{m}^{2}\right)$. The effect modification of the corresponding baseline hematologic parameters and general characteristics on the associations of BTX exposure with decline in hematologic parameters were evaluated by additionally including an interaction term of BTX components (continuous) and stratified variable (categorical) in covariate-adjusted linear regression models. We also calculated the corresponding FDR-adjusted $P_{\text {interaction }}$ to adjust for multiple testing. 
We used generalized weighted quantile sum (gWQS) regression to evaluate the combined health effects of all BTX components and identify the contribution of each component (Czarnota et al. 2015). We scored each BTX component into quartiles, and split the data into training and validation sets by $40 \% / 60 \%$ to estimate the WQS index weights $(w)$ for each component and test the statistical significance of the WQS index which is the weighted index for the set of chemicals of interest, respectively. We conducted a $B=100$ bootstrap sampling to estimate the stability selection of $w$ by maximizing the likelihood for the models. We estimated the combined effects of BTX components according to the covariate-adjusted associations ( $\beta$ and $P_{\text {trend }}$ ) of their WQS index with the decline in hematologic parameters, and identified the contribution of each component based on its weight $(w)$ in WQS index.

To estimate BMD, we divided our subjects into 7-8 subgroups according to the CED distributions of BTX components, to make sure that each subgroup had a clear CED range for BTX components and had an appropriate sample size in the range of 70 to 200 subjects (Table S4). We used the median value of the corresponding BTX components in each subgroup as its exposure level (Table S4). We estimated the BMD and BMDL for each BTX component in the total population by Benchmark Dose Software (BMDS) based on the technical guidance proposed by U.S. EPA (EPA/100/R-12/001) (EPA 2012). BMR was set at default value of a $10 \%$ extra risk of hematological damages. We tested all models for dichotomous data, including Dichotomous-Hill, Gamma, Log-Logistic, Multistage, Weibull, Logistic, Log-Probit, and Probit. We selected the models that fit our data adequately (i.e., $P$ values for good-of-fit tests $>0.1$ ), and then pick the best model according to the following criteria recommended by EPA guidance: BMD not higher than the maximum dose; $\mathrm{BMD} / \mathrm{BMDL}<3$; and the lowest Akaike's Information Criterion (AIC).

The analysis of combined effects of BTX components were performed by gWQS package in R (version 4.0.5); BMD and BMDL were calculated by BMDS (Version 3.20); and other statistical analyses were conducted by SPSS statistical software package 20.0 (Chicago, IL, USA). All statistic tests were two-tailed and considered to be significant at $P<0.05$.

\section{Results}

For three years prior to the baseline survey, we collected a total of 510 duplicate ambient samples from our participants' worksites (Table S2). The mean 8h-TWA concentrations of benzene, toluene, and xylene were $0.012 \mathrm{mg} / \mathrm{m}^{3}, 0.024 \mathrm{mg} / \mathrm{m}^{3}$, and $0.068 \mathrm{mg} / \mathrm{m}^{3}$, respectively, and were significantly modestly correlated with each other (Spearman correlation coefficients 0.440-0.502, all $P<0.001$ ) (Table S5). We found that the annual average 8h-TWA concentrations of all BTX components were not significantly different (all $P>0.05$ ) (Figure S1), suggesting that BTX concentrations in BEPWC participants' workplaces were relatively stable. Thus, we used three-year average 8h-TWA concentrations to calculate BTX CED levels for individual BEPWC participants.

Table 1 and Table $\mathbf{S 6}$ showed baseline general characteristics and BTX CED levels for the subject in the present study ( $n=1054$, i.e., those who had undergone hematologic parameter detection in both stages) and for the total population of BEPWC cohort $(n=1443)$, respectively. We found that the subject in the 
present study were relatively young (at the mean age of 39.91), mostly male (77.42\%) and nonsmokers $(67.46 \%)$, and had relative long duration of occupational BTX exposure (with mean work years of 18.75) (Table 1). The median CED levels of benzene, toluene, and xylene were $0.65,0.84$, and $1.37 \mathrm{mg} / \mathrm{m}^{3}$ xyear, respectively (Table 1). In the correlation substudy of benzene CED levels and urinary SPMA concentrations, we observed that urinary SPMA concentrations were significantly increased with the increasing of benzene CED levels $\left(P_{\text {trend }}=0.032\right)$ (Figure S2).

Table 1

Baseline general characteristics and BTX CED levels in BEPWC participants in the present study $(n=1054)$.

\begin{tabular}{|ll|}
\hline Variables & Mean \pm SD, $\mathbf{n}$ (\%), or median (25th percentile, 75th percentile) \\
\hline Baseline general characteristics & \\
\hline Age (years) & $39.91 \pm 6.57$ \\
\hline Sex (male, \%) & $816(77.42)$ \\
\hline Smoking status (smoker, \%) & $343(32.54)$ \\
\hline Drinking status (drinker, \%) & $493(46.77)$ \\
\hline Factory location (Guangzhou, \%) & $387(36.72)$ \\
\hline BMl (kg/m $\left.{ }^{3}\right)$ & $23.33 \pm 3.11$ \\
\hline Pack-years of smoking & $2.84 \pm 6.13$ \\
\hline Work years of exposure (years) & $18.75 \pm 7.70$ \\
\hline BTX CED levels (mg/m ${ }^{3}$ xyear) & \\
\hline Benzene & $0.65(0.36,1.03)$ \\
\hline Toluene & $0.84(0.56,1.23)$ \\
\hline Xylene & $1.37(0.71,2.40)$ \\
\hline Note: Abbreviation: BMl, body mass index; CED, cumulative exposure doses.
\end{tabular}

Furthermore, we also observed that the levels of most hematologic parameters, except for WBC counts, neutrophil counts, hematocrit, and platelet counts, were significantly changed after four-year follow-up (all $P<0.05$ ) (Table 2). When compared to baseline levels, MCV were significantly increased, while other hematologic parameters were significantly decreased with their mean decline values greater than 0 (Table 2). Then we compared the magnitude of decline in hematologic parameters between subjects with different general characteristics (Table S7). We found that after adjusting for other primary covariables, some hematologic parameters showed greater decline in subjects over the age of 40 , smokers, and 
subjects with $\mathrm{BMl}<24 \mathrm{~kg} / \mathrm{m}^{2}$, while the decline in some parameters showed significant sex differences $(P$ $<0.05)$ (Table S7). 
Table 2

Hematologic parameters in both stages and their decline for BEPWC participants in the present study.

$\begin{array}{lllll}\begin{array}{l}\text { Hematologic } \\ \text { parameters }^{\mathrm{a}}\end{array} & \begin{array}{l}\text { Baseline } \\ \text { stage }\end{array} & \begin{array}{l}\text { Follow-up } \\ \text { stage }\end{array} & \begin{array}{l}P \text { value } \\ \text { b }\end{array} & \begin{array}{l}\text { Decline in hematologic } \\ \text { parameters }^{c}\end{array}\end{array}$

Leukocyte differential count

\begin{tabular}{lllll} 
WBC $\left(\times 10^{9} / \mathrm{L}\right)$ & $6.49 \pm 1.58$ & $6.41 \pm 2.47$ & 0.287 & $0.08 \pm 2.35$ \\
\hline Neutrophils $\left(\times 10^{9} / \mathrm{L}\right)$ & $3.54 \pm 1.15$ & $3.57 \pm 1.17$ & 0.293 & $-0.03 \pm 1.03$ \\
\hline Monocytes $\left(\times 10^{9} / \mathrm{L}\right)$ & $0.47 \pm 0.23$ & $0.32 \pm 0.12$ & $<0.001$ & $0.15 \pm 0.22$ \\
\hline Lymphocytes $\left(\times 10^{9} / \mathrm{L}\right)$ & $2.42 \pm 0.67$ & $2.27 \pm 0.65$ & $<0.001$ & $0.15 \pm 0.54$
\end{tabular}

RBC indices

$\begin{array}{lllll}\text { RBC }\left(\times 10^{12} / \mathrm{L}\right) & 5.05 \pm 0.60 & 4.97 \pm 0.58 & <0.001 & 0.08 \pm 0.39 \\ \text { Hemoglobin }(\mathrm{g} / \mathrm{L}) & 152.10 \pm & 143.76 \pm & <0.001 & 8.34 \pm 13.85 \\ & 17.93 & 14.69 & & \\ \text { Hematocrit }(\%) & 43.76 \pm 4.88 & 43.62 \pm 3.87 & 0.256 & 0.14 \pm 3.90 \\ \text { MCV }(\mathrm{fL}) & 87.32 \pm 8.07 & 88.53 \pm 8.50 & <0.001 & -1.21 \pm 3.23 \\ \text { MCHC (g/L) } & 347.53 \pm & 329.20 \pm & <0.001 & 18.33 \pm 12.05 \\ & 12.34 & 10.12 & & \end{array}$

$\mathrm{MCH}(\mathrm{pg}) \quad 30.34 \pm 3.29 \quad 29.18 \pm 3.20 \quad<0.001 \quad 1.16 \pm 1.63$

Platelet indices

$\begin{array}{lllll}\text { Platelet }\left(\times 10^{9} / \mathrm{L}\right) & 243.60 \pm & 241.90 \pm & 0.152 & 1.70 \pm 38.07 \\ & 58.01 & 54.67 & & \end{array}$

\begin{tabular}{lllll} 
MPV (fL) & $9.52 \pm 1.18$ & $9.03 \pm 1.40$ & $<0.001$ & $0.49 \pm 0.74$ \\
\hline PDW (\%) & $15.09 \pm 2.07$ & $14.72 \pm 2.05$ & $<0.001$ & $0.37 \pm 1.11$ \\
\hline Plateletcrit (\%) & $0.23 \pm 0.05$ & $0.22 \pm 0.05$ & $<0.001$ & $0.01 \pm 0.05^{1}$
\end{tabular}

Note: Abbreviation: WBC, white blood cell count; RBC, red blood cell count; MCV, Erythrocyte mean corpuscular volume; $\mathrm{MCHC}$, mean corpuscular hemoglobin concentration; $\mathrm{MCH}$, mean corpuscular hemoglobin; MPV, mean platelet volume; PDW, platelet distribution width.

a Values of variables were shown by mean \pm SD.

${ }^{b}$ Paired Student $t$-test.

${ }^{c}$ The decline for all hematologic parameters were calculated by the levels measured in baseline stage minus the corresponding levels measured in the follow-up stage. 
We first used confounder-adjusted linear regression models to evaluate the associations of single BTX components with the decline in hematologic parameters in the total population (Table 3). We found that after FDR adjustment, benzene CED levels were positively associated with the decline in monocyte counts $\left(\beta=0.012, P_{\text {trend }}=0.007\right)$, and toluene CED levels were negatively associated with the decline in $\mathrm{MCHC}$ $\left(\beta=-0.905, P_{\text {trend }}=0.016\right)$ (Table 3). 
Table 3

Associations of BTX CED levels with the decline in hematologic parameters.

\begin{tabular}{|c|c|c|c|c|c|c|}
\hline \multirow{2}{*}{$\begin{array}{l}\text { Decline in } \\
\text { hematologic } \\
\text { parameters }\end{array}$} & \multicolumn{2}{|l|}{ Benzene } & \multicolumn{2}{|l|}{ Toluene } & \multicolumn{2}{|l|}{ Xylene } \\
\hline & $\stackrel{\beta}{(95 \% \mathrm{Cl})}$ & $P_{\text {trend }}{ }^{a}$ & $\beta(95 \% \mathrm{Cl})$ & $P_{\text {trend }}{ }^{a}$ & $\beta(95 \% \mathrm{Cl})$ & $\begin{array}{l}P_{\text {trend }} \\
\text { a }\end{array}$ \\
\hline \multicolumn{7}{|c|}{ Leukocyte differential count } \\
\hline WBC & $\begin{array}{l}0.047 \\
(-0.127 \\
0.221)\end{array}$ & 0.596 & $\begin{array}{l}0.018(-0.170 \\
0.206)\end{array}$ & 0.855 & $\begin{array}{l}0.025(-0.200 \\
0.250)\end{array}$ & 0.825 \\
\hline Neutrophils & $\begin{array}{l}0.011 \\
(-0.062 \\
0.084)\end{array}$ & 0.761 & $\begin{array}{l}-0.029(-0.107 \\
0.049)\end{array}$ & 0.460 & $\begin{array}{l}-0.027(-0.121 \\
0.067)\end{array}$ & 0.572 \\
\hline Monocytes & $\begin{array}{l}0.012 \\
(0.004 \\
0.020)\end{array}$ & $0.007 *$ & $\begin{array}{l}0.003(-0.007 \\
0.013)\end{array}$ & 0.478 & $\begin{array}{l}0.005(-0.007 \\
0.017)\end{array}$ & 0.368 \\
\hline Lymphocytes & $\begin{array}{l}0.031 \\
(-0.006 \\
0.068)\end{array}$ & 0.104 & $\begin{array}{l}0.047(0.008 \\
0.086)\end{array}$ & 0.021 & $\begin{array}{l}0.041(-0.006 \\
0.088)\end{array}$ & 0.091 \\
\hline \multicolumn{7}{|l|}{ RBC indices } \\
\hline RBC & $\begin{array}{l}-0.004 \\
(-0.026 \\
0.018)\end{array}$ & 0.698 & $\begin{array}{l}0.010(-0.014 \\
0.034)\end{array}$ & 0.376 & $\begin{array}{l}0.014(-0.013 \\
0.041)\end{array}$ & 0.315 \\
\hline Hemoglobin & $\begin{array}{l}0.093 \\
(-0.526 \\
0.712)\end{array}$ & 0.769 & $\begin{array}{l}0.202(-0.470 \\
0.874)\end{array}$ & 0.556 & $\begin{array}{l}0.436(-0.360 \\
1.232)\end{array}$ & 0.282 \\
\hline Hematocrit & $\begin{array}{l}0.137 \\
(-0.045 \\
0.319)\end{array}$ & 0.143 & $\begin{array}{l}0.189(-0.009 \\
0.387)\end{array}$ & 0.061 & $\begin{array}{l}0.259(0.022 \\
0.496)\end{array}$ & 0.032 \\
\hline MCV & $\begin{array}{l}0.271 \\
(0.030 \\
0.512)\end{array}$ & 0.028 & $\begin{array}{l}0.122(-0.141 \\
0.385)\end{array}$ & 0.361 & $\begin{array}{l}0.152(-0.162 \\
0.466)\end{array}$ & 0.342 \\
\hline $\mathrm{MCHC}$ & $\begin{array}{l}-0.735 \\
(-1.417 \\
-0.053)\end{array}$ & 0.035 & $\begin{array}{l}-0.905(-1.644, \\
-0.166)\end{array}$ & $0.016 *$ & $\begin{array}{l}-0.337(-1.221 \\
0.547)\end{array}$ & 0.455 \\
\hline $\mathrm{MCH}$ & $\begin{array}{l}0.044 \\
(-0.068 \\
0.156)\end{array}$ & 0.439 & $\begin{array}{l}-0.025(-0.147 \\
0.097)\end{array}$ & 0.694 & $\begin{array}{l}-0.002(-0.147 \\
0.143)\end{array}$ & 0.974 \\
\hline \multicolumn{7}{|l|}{$\begin{array}{l}\text { Platelet } \\
\text { indices }\end{array}$} \\
\hline Platelet & $\begin{array}{l}1.401 \\
(-1.198 \\
4.000)\end{array}$ & 0.291 & $\begin{array}{l}-0.021 \\
2.799)\end{array}(-2.841$ & 0.988 & $\begin{array}{l}0.935(-2.430 \\
4.300)\end{array}$ & 0.586 \\
\hline
\end{tabular}




\begin{tabular}{|c|c|c|c|c|c|c|}
\hline \multirow{2}{*}{$\begin{array}{l}\text { Decline in } \\
\text { hematologic } \\
\text { parameters }\end{array}$} & \multicolumn{2}{|l|}{ Benzene } & \multicolumn{2}{|l|}{ Toluene } & \multicolumn{2}{|l|}{ Xylene } \\
\hline & $\begin{array}{l}\beta \\
(95 \% \mathrm{Cl})\end{array}$ & $P_{\text {trend }}{ }^{a}$ & $\beta(95 \% \mathrm{Cl})$ & $P_{\text {trend }}{ }^{a}$ & $\beta(95 \% \mathrm{Cl})$ & $\begin{array}{l}P_{\text {trend }} \\
\mathrm{a}\end{array}$ \\
\hline MPV & $\begin{array}{l}0.002 \\
(-0.041 \\
0.045)\end{array}$ & 0.927 & $\begin{array}{l}0.009(-0.038 \\
0.056)\end{array}$ & 0.723 & $\begin{array}{l}0.026(-0.031 \\
0.083)\end{array}$ & 0.362 \\
\hline PDW & $\begin{array}{l}0.002 \\
(-0.069 \\
0.073)\end{array}$ & 0.949 & $\begin{array}{l}0.015(-0.061 \\
0.091)\end{array}$ & 0.689 & $\begin{array}{l}0.038(-0.052 \\
0.128)\end{array}$ & 0.412 \\
\hline Plateletcrit & $\begin{array}{l}0.001 \\
(-0.001 \\
0.003)\end{array}$ & 0.646 & $\begin{array}{l}-1.93 \times 10^{-4} 0.002 \\
0.002)\end{array}$ & 0.896 & $\begin{array}{l}3.29 \times 10^{-4}(-0.004 \\
0.004)\end{array}$ & 0.852 \\
\hline $\begin{array}{l}\text { Note: Abbrevi } \\
\text { corpuscular v } \\
\text { hemoglobin; } \\
\text { a Generalized } \\
\text { years of smok } \\
\text { * FDR-adjuste }\end{array}$ & $\begin{array}{l}\text { n: WBC, w } \\
\text { me; MCHC } \\
\text { V, mean pla } \\
\text { ear model } \\
\text {, drinking } \\
\text { trend }<0.05\end{array}$ & $\begin{array}{l}\text { ite blood } \\
\text { nean corp } \\
\text { elet volum } \\
\text { ith adjust } \\
\text { atus, and }\end{array}$ & $\begin{array}{l}\text { Il count; RBC, red bl } \\
\text { Iscular hemoglobin } \\
\text {; PDW, platelet dist } \\
\text { ent for age, sex, fac } \\
\text { he baseline hemato }\end{array}$ & $\begin{array}{l}\text { d cell col } \\
\text { oncentrati } \\
\text { ution wid } \\
\text { ry locatio } \\
\text { gic param }\end{array}$ & $\begin{array}{l}\text { t; MCV, Erythrocyte } \\
\text { n; MCHC, mean corp } \\
\text { BMI, smoking statu } \\
\text { ters. }\end{array}$ & $\begin{array}{l}\text { an } \\
\text { cular } \\
\text { pack- }\end{array}$ \\
\hline
\end{tabular}

We performed stratification analysis according to the baseline hematologic parameters and some important general characteristics, and then evaluated their effect modification on the associations of BTX exposure on the decline in hematologic parameters (Table 4 and Table S8-S13). We interestingly observed that the associations of BTX components with the decline in hematologic parameters were mostly significantly stronger in subjects with higher baseline hematologic parameters, males, drinkers, and subjects with BMl $\geq 24 \mathrm{~kg} / \mathrm{m}^{2}$ (all FDR-adjusted $P_{\text {interaction }}<0.05$ ) (Table 4). Specifically, the positive associations of xylene with the decline in monocyte counts $(\beta=0.053)$; of toluene and xylene with the decline in RBC counts and hematocrit $(\beta>0.055)$, and of toluene with the decline in hemoglobin concentrations $(\beta=1.647)$ were significant and more pronounced in workers with higher baseline values; the positive associations of xylene with the decline in counts of lymphocytes $(\beta=0.061)$ and RBC $(\beta=$ 0.032), and of benzene, toluene, and xylene with the decline in hematocrit $(\beta \geq 0.200)$ were all significant and more pronounced in male workers; and the positive associations of toluene and/or xylene with the decline in lymphocyte counts $(\beta>0.065)$ were significant and more pronounced in nondrinkers and in workers with BMI $\geq 24 \mathrm{~kg} / \mathrm{m}^{2}$ (all FDR-adjusted $P_{\text {interaction }}<0.05$ ) (Table 4).

However, we also found that the associations of benzene with the decline in monocytes $(\beta=0.015)$, and of xylene with the decline in $\mathrm{MCHC}(\beta=-1.961)$ were significant and more pronounced in workers with lower baseline values (all FDR-adjusted $P_{\text {interaction }}<0.05$ ) (Table 4). Furthermore, the negative association of benzene with the decline in $\mathrm{MCH}(\beta=-0.116)$ was significant and more pronounced in workers $\leq 40$ years old (FDR-adjusted $P_{\text {interaction }}<0.05$ ) (Table 4). Although cigarette smoke is an important 
environmental BTX source, we didn't observe any modification effects of smoking status on these associations (all FDR-adjusted $P_{\text {interaction }}>0.05$ ) (Table S14). 
Table 4

Significanta modification effects on the associations of BTX CED levels with decline in hematologic parameters.

\begin{tabular}{|c|c|c|c|c|c|}
\hline $\begin{array}{l}\text { BTX } \\
\text { components }\end{array}$ & $\begin{array}{l}\text { Decline in } \\
\text { hematologic } \\
\text { parameters }\end{array}$ & \multicolumn{3}{|c|}{$\begin{array}{l}\text { Associations }[\beta(95 \% \mathrm{Cl})]^{\mathrm{b}} \text { in different } \\
\text { subgroups }\end{array}$} & \multirow[t]{2}{*}{$P_{\text {interactionc }}$} \\
\hline \multicolumn{2}{|c|}{ Stratified by baseline parameters ${ }^{d}$} & Low & Medium & High & \\
\hline Benzene & Monocytes & $\begin{array}{l}0.015(0.001 \\
0.029) \S\end{array}$ & $\begin{array}{l}0.004(-0.010 \\
0.018)\end{array}$ & $\begin{array}{l}0.026 \\
(-0.009 \\
0.061)\end{array}$ & 0.008 \\
\hline Toluene & Monocytes & $\begin{array}{l}0.009(-0.005 \\
0.023)\end{array}$ & $\begin{array}{l}1.98 \times 10^{-4} \\
(-0.015 \\
0.016)\end{array}$ & $\begin{array}{l}0.021 \\
(-0.020 \\
0.062)\end{array}$ & $8.70 \times 10^{-5 *}$ \\
\hline Xylene & Monocytes & $\begin{array}{l}0.011(-0.007 \\
0.029)\end{array}$ & $\begin{array}{l}-0.006(-0.024 \\
0.012)\end{array}$ & $\begin{array}{l}0.053 \\
(0.004 \\
0.102) \S\end{array}$ & $2.56 \times 10^{-9}$ * \\
\hline Toluene & RBC & $\begin{array}{l}-0.012(-0.045 \\
0.021)\end{array}$ & $\begin{array}{l}0.016(-0.023 \\
0.055)\end{array}$ & $\begin{array}{l}0.059 \\
(0.006 \\
0.112) \S\end{array}$ & $0.027 *$ \\
\hline Xylene & RBC & $\begin{array}{l}-4.90 \times 10^{-4} \\
(-0.042,0.041)\end{array}$ & $\begin{array}{l}2.96 \times 10^{-4} \\
(-0.047 \\
0.047)\end{array}$ & $\begin{array}{l}0.085 \\
(0.028, \\
0.142) \S\end{array}$ & $4.96 \times 10^{-5 *}$ \\
\hline Toluene & Hemoglobin & $\begin{array}{l}-0.292(-1.515 \\
0.931)\end{array}$ & $\begin{array}{l}0.201(-0.779 \\
1.181)\end{array}$ & $\begin{array}{l}1.647 \\
(0.120, \\
3.174) \S\end{array}$ & $0.012^{*}$ \\
\hline Toluene & Hematocrit & $\begin{array}{l}0.153(-0.186 \\
0.492)\end{array}$ & $\begin{array}{l}0.006(-0.286 \\
0.298)\end{array}$ & $\begin{array}{l}0.555 \\
(0.063, \\
1.047)^{\S}\end{array}$ & $0.014^{*}$ \\
\hline Xylene & Hematocrit & $\begin{array}{l}0.235(-0.184 \\
0.654)\end{array}$ & $\begin{array}{l}-0.030(-0.387 \\
0.327)\end{array}$ & $\begin{array}{l}0.780 \\
(0.247 \\
1.313) \S\end{array}$ & $0.001 *$ \\
\hline Xylene & $\mathrm{MCHC}$ & $\begin{array}{l}-1.961(-3.799 \\
-0.123)^{\S}\end{array}$ & $\begin{array}{l}0.486(-0.962 \\
1.934)\end{array}$ & $\begin{array}{l}0.008 \\
(-1.493 \\
1.509)\end{array}$ & $1.62 \times 10^{-8 *}$ \\
\hline Benzene & Plateletcrit & $\begin{array}{l}0.002(-0.002 \\
0.006)\end{array}$ & $\begin{array}{l}0.002(-0.002 \\
0.006)\end{array}$ & $\begin{array}{l}-0.004 \\
(-0.012 \\
0.004)\end{array}$ & $2.79 \times 10^{-4 \star}$ \\
\hline Toluene & Plateletcrit & $\begin{array}{l}-0.002(-0.006 \\
0.002)\end{array}$ & $\begin{array}{l}0.001(-0.003 \\
0.005)\end{array}$ & $\begin{array}{l}-0.005 \\
(-0.013 \\
0.003)\end{array}$ & $0.005^{\star}$ \\
\hline Stratified by a & & $\leq 40$ & $>40$ & & \\
\hline
\end{tabular}




\begin{tabular}{|c|c|c|c|c|}
\hline \multirow{2}{*}{$\begin{array}{l}\begin{array}{l}\text { BTX } \\
\text { components }\end{array} \\
\text { Benzene }\end{array}$} & \multirow{2}{*}{$\begin{array}{l}\text { Decline in } \\
\text { hematologic } \\
\text { parameters }\end{array}$} & \multicolumn{2}{|c|}{$\begin{array}{l}\text { Associations }[\beta(95 \% \mathrm{Cl})]^{\mathrm{b}} \text { in different } \\
\text { subgroups }\end{array}$} & \multirow{2}{*}{$\begin{array}{l}P_{\text {interactionc }} \\
0.010^{\star}\end{array}$} \\
\hline & & $\begin{array}{l}-0.116(-0.222 \\
-0.010) \S\end{array}$ & $\begin{array}{l}0.235(-0.006 \\
0.476)\end{array}$ & \\
\hline \multicolumn{2}{|c|}{ Stratified by sex } & Female & Male & \\
\hline Xylene & Lymphocytes & $\begin{array}{l}0.044(-0.032 \\
0.120)\end{array}$ & $\begin{array}{l}0.061(0.002 \\
0.120) \S\end{array}$ & $0.001 *$ \\
\hline Xylene & RBC & $\begin{array}{l}-0.026(-0.081 \\
0.029)\end{array}$ & $\begin{array}{l}0.032(0.001 \\
0.063) \S\end{array}$ & $0.001 *$ \\
\hline Benzene & Hematocrit & $\begin{array}{l}-0.347(-0.917 \\
0.223)\end{array}$ & $\begin{array}{l}0.206(0.022 \\
0.390) \S\end{array}$ & $0.033^{*}$ \\
\hline Toluene & Hematocrit & $\begin{array}{l}-0.420(-1.067 \\
0.227)\end{array}$ & $\begin{array}{l}0.271(0.073 \\
0.469) \S\end{array}$ & $0.011^{*}$ \\
\hline Xylene & Hematocrit & $\begin{array}{l}-0.249(-0.870 \\
0.372)\end{array}$ & $\begin{array}{l}0.401(0.150 \\
0.652) \S\end{array}$ & $0.033^{*}$ \\
\hline \multicolumn{2}{|c|}{ Stratified by drinking status } & Nondrinker & Drinker & \\
\hline Benzene & Lymphocytes & $\begin{array}{l}0.045(-0.006 \\
0.096)\end{array}$ & $\begin{array}{l}0.025(-0.030 \\
0.080)\end{array}$ & $0.030 *$ \\
\hline Toluene & Lymphocytes & $\begin{array}{l}0.068(0.013 \\
0.123) \S\end{array}$ & $\begin{array}{l}0.026(-0.033 \\
0.085)\end{array}$ & $0.033^{*}$ \\
\hline \multicolumn{2}{|c|}{ Stratified by BMI $\left(\mathrm{kg} / \mathrm{m}^{2}\right)$} & $<24$ & $\geq 24$ & \\
\hline Benzene & Neutrophils & $\begin{array}{l}-0.017(-0.111, \\
0.077)\end{array}$ & $\begin{array}{l}0.065(-0.049 \\
0.179)\end{array}$ & $0.012^{\star}$ \\
\hline Toluene & Neutrophils & $\begin{array}{l}-0.101(-0.205 \\
0.003)\end{array}$ & $\begin{array}{l}0.070(-0.050 \\
0.190)\end{array}$ & $0.001 *$ \\
\hline Toluene & Lymphocytes & $\begin{array}{l}0.016(-0.037 \\
0.069)\end{array}$ & $\begin{array}{l}0.086(0.023 \\
0.149) \S\end{array}$ & $0.029 *$ \\
\hline Xylene & Lymphocytes & $\begin{array}{l}0.010(-0.049 \\
0.069)\end{array}$ & $\begin{array}{l}0.093(0.011 \\
0.175)^{\S}\end{array}$ & $0.023^{*}$ \\
\hline
\end{tabular}




\begin{tabular}{|llll|}
$\begin{array}{l}\text { BTX } \\
\text { components }\end{array}$ & $\begin{array}{l}\text { Decline in } \\
\text { hematologic } \\
\text { parameters }\end{array}$ & $\begin{array}{l}\text { Associations }[\beta(95 \% \mathrm{Cl})]^{\mathrm{b}} \text { in different } \\
\text { subgroups }\end{array}$ & $P_{\text {interactionc }}$ \\
\hline
\end{tabular}

Note: Abbreviation: RBC, red blood cell count; MCV, Erythrocyte mean corpuscular volume; MCHC, mean corpuscular hemoglobin concentration; MCHC, mean corpuscular hemoglobin.

a This table only showed the significant modification effects with FDR-adjusted $P_{\text {interaction }}<0.05$;

${ }^{b}$ Generalized linear model with adjustment for age, sex, factory location, BMI, smoking status, packyears of smoking, drinking status, and/or baseline hematologic parameters when appropriate.

${ }^{\mathrm{c}} P_{\text {interaction }}$ were calculated by modeling an interaction term of single BTX components and stratified variables in generalized linear models, with adjustment for age, sex, factory location, BMI, smoking status, pack-years of smoking, drinking status, and/or baseline hematologic parameters when appropriate.

d Subjects were divided to three tertile (low, medium, and high) groups according to the cut-off of 33rd percentile and 67 th percentile of the baseline levels of hematologic parameters.

$\S P_{\text {trend }}<0.05 ; *$ FDR-adjusted $P_{\text {interaction }}<0.05$.

As human beings are often co-exposed to multiple pollutants rather than a single pollutant, we evaluated the combined effects of BTX components on the decline in hematologic parameters and identified the contribution of each BTX component based on gWQS regression models (Table 5). We found that the coexposure of BTX components had positive effects on the decline in monocyte counts, RBC counts, and hemoglobin concentrations ( $P_{\text {trend }}$ for WQS index were all $<0.05$ ). Specifically, a quartile increase of WQS $_{\text {MOE }}$ index was associated with $0.013 \times 10^{9} / \mathrm{L}$ decline in monocyte counts $\left(P_{\text {trend }}=0.007\right)$, and benzene was the most highly weighted component $(w=0.976)$ in the $W_{\text {QSOE }}$ index; a quartile increase of WQS $_{\mathrm{RBC}}$ index was associated with $0.045 \times 10^{12} / \mathrm{L}$ decline in RBC counts $\left(P_{\text {trend }}=0.002\right)$, and toluene was the most highly weighted component $(w=0.614)$ in the $W_{Q S} S_{R B C}$ index; and a quartile increase of $W Q S_{H b}$ index was associated with $0.972 \mathrm{~g} / \mathrm{L}$ decline in hemoglobin concentrations $\left(P_{\text {trend }}=0.040\right)$, and xylene was the most highly weighted component $(w=0.847)$ in $W_{\mathrm{H}} \mathrm{S}_{\mathrm{Hb}}$ index (Table 5).

Table 5. Associations of the WQS regression index with the decline in hematologic parameters. 


\begin{tabular}{|c|c|c|c|c|c|c|}
\hline \multirow{2}{*}{$\begin{array}{l}\text { Decline in In-transformed } \\
\text { hematologic parameters }\end{array}$} & \multirow{2}{*}{ WQS index } & \multirow{2}{*}{$\begin{array}{c}\beta(95 \% \mathrm{CI}) \text { for } \mathrm{WQS} \\
\text { index }^{\mathrm{a}}\end{array}$} & \multirow{2}{*}{$P_{\text {trend }}{ }^{\mathrm{a}}$} & \multicolumn{3}{|c|}{ Weight for each BTX component ${ }^{b}$} \\
\hline & & & & Benzene & Toluene & Xylene \\
\hline \multicolumn{7}{|c|}{ Leukocyte differential count } \\
\hline WBC & WQSwBC & $0.175(-0.107,0.457)$ & 0.226 & 0.677 & 0.099 & 0.224 \\
\hline Neutrophils & WQS $S_{\text {NEUT }}$ & $0.008(-0.096,0.112)$ & 0.878 & 0.26 & 0.425 & 0.315 \\
\hline Monocytes & WQS $_{\text {MOE }}$ & $0.013(0.003,0.023)$ & $0.007^{*}$ & 0.976 & 0 & 0.024 \\
\hline Lymphocytes & $\mathrm{WQS}_{\mathrm{L} Y M}$ & $0.005(-0.050,0.060)$ & 0.851 & 0.038 & 0.303 & 0.659 \\
\hline \multicolumn{7}{|l|}{$\mathrm{RBC}$ indices } \\
\hline $\mathrm{RBC}$ & $\mathrm{WQS}_{\mathrm{RBC}}$ & $0.045(0.018,0.072)$ & $0.002^{*}$ & 0 & 0.614 & 0.386 \\
\hline Hemoglobin & $\mathrm{WQS}_{\mathrm{Hb}}$ & $0.972(0.045,1.899)$ & $0.040^{*}$ & 0.073 & 0.08 & 0.847 \\
\hline Hematocrit & WQSHCT & $0.162(-0.112,0.436)$ & 0.248 & 0.009 & 0.153 & 0.838 \\
\hline $\mathrm{MCV}$ & WQSMCV & $0.099(-0.226,0.424)$ & 0.550 & 0.43 & 0.298 & 0.271 \\
\hline $\mathrm{MCHC}$ & WQSMCHC & $-0.002(-0.953,0.949)$ & 0.996 & 0 & 0 & 1 \\
\hline $\mathrm{MCH}$ & WQSMCH & $-0.068(-0.199,0.063)$ & 0.308 & 0.843 & 0.066 & 0.091 \\
\hline \multicolumn{7}{|l|}{ Platelet indices } \\
\hline Platelet & WQSpLT & $0.147(-3.810,4.104)$ & 0.942 & 0.049 & 0.443 & 0.508 \\
\hline MPV & $\mathrm{WQS}_{\mathrm{MPV}}$ & $-0.032(-0.091,0.027)$ & 0.282 & 0.078 & 0.498 & 0.424 \\
\hline PDW & WQSppw & $-0.023(-0.105,0.059)$ & 0.584 & 0.028 & 0.829 & 0.143 \\
\hline Plateletcrit & WQSpcT & $-0.001(-0.005,0.003)$ & 0.683 & 0.828 & 0.011 & 0.161 \\
\hline
\end{tabular}

Note: Abbreviation: WQS, weighted quantile sum; WBC, white blood cell count; RBC, red blood cell count; $\mathrm{MCV}$, Erythrocyte mean corpuscular volume; $\mathrm{MCHC}$, mean corpuscular hemoglobin concentration; $\mathrm{MCHC}$, mean corpuscular hemoglobin; MPV, mean platelet volume; PDW, platelet distribution width.

${ }^{a}$ Estimated $\beta$ are associated with a unit increase in the WQS index which are calculated by gWQS regression model with adjustment for age, sex, factory location, BMI, smoking status, pack-years of smoking, drinking status, and corresponding baseline hematologic parameters.

${ }^{b}$ The gray scale reflects the magnitude of weights. The deeper the color, the higher the weight.

According to the previous-mentioned criteria (for detailed information, see " 2.5 Evaluation of hematological changes and damages"), 171 subjects had been classified as the cases of hematological damages (Table S4). According to the criteria recommended by EPA guidance (for detailed information, see "2.6 Statistical analysis"), Multistage model was considered as the optimal model for benzene; Dichotomous Hill model was selected as the best model for toluene; and Probit model was selected as the best model for xylene (Table 6). The Multistage dose-response model formula was $P[\mathrm{X}]=$ background $+(1$-background $) \times\left[1\right.$-exp(-slope $\times X X-$ slope $\left.\left._{2} \times X^{2}-\ldots\right)\right]$. The Dichotomous Hill dose-response model formula was $P[\mathrm{X}]=$ background $+(\mathrm{v}-\mathrm{v} \times$ background $) /[1+\exp ($-intercept-slope $\times \log (\mathrm{X}))]$, where $\mathrm{v}$ is the maximum probability of response predicted by the model. The Probit dose-response model formula was $P[\mathrm{X}]=$ CumNorm(intercept + slopexX). At 10\% of the BMR level, the BMD (and BMDL) for CED levels of benzene, 
toluene, and xylene were 2.138 (1.559), 1.449 (1.325), and 2.937 (2.312) mg/m³xyear, respectively (Table 6). The dose-response curves for individual BTX components were shown in Figure S3.

Table 6. Estimated BMD and BMDL for BTX components based on hematological effects.

\begin{tabular}{|lllllll|}
\hline $\begin{array}{l}\text { BTX } \\
\text { components }\end{array}$ & Model name & $\begin{array}{l}\text { Chi- } \\
\text { square }\end{array}$ & $\begin{array}{l}P \text { for } \\
\text { good-of-fit } \\
\text { tests }\end{array}$ & AlC & BMD & BMDL \\
Benzene & Multistage & 6.017 & 0.421 & 777.588 & 2.138 & 1.559 \\
\hline Toluene & $\begin{array}{l}\text { Dichotomous } \\
\text { Hill }\end{array}$ & 4.322 & 0.364 & 704.276 & 1.449 & 1.325 \\
\hline Xylene & Probit & 5.669 & 0.461 & 741.547 & 2.937 & 2.312 \\
\hline $\begin{array}{l}\text { Note: Abbreviation: AlC, Akaike's Information Criterion; BMD, benchmark doses; BMDL, lower } \\
\text { confidence limit of BMD. }\end{array}$
\end{tabular}

In real life, there is a significant variation among individual workers in working duration. In order to protect BTX-exposed workers as much as possible, we calculated REL-TWA concentrations by dividing the estimated BMDLs by 40 years, which might be a relatively long working duration for workers who start working at the age of 20 and retiring at the legal retirement age of 60 in China. The REL-TWA for benzene, toluene, and xylene were $0.0390 \mathrm{mg} / \mathrm{m}^{3}$ (about $0.0125 \mathrm{ppm}$ ), $0.0331 \mathrm{mg} / \mathrm{m}^{3}$ (about $0.0088 \mathrm{ppm}$ ), and $0.0578 \mathrm{mg} / \mathrm{m}^{3}$ (about $0.0122 \mathrm{ppm}$ ), respectively.

\section{Discussion}

In order to evaluate the health effects of long-term occupational BTX co-exposure, we established BEPWC cohort. We observed a significant decrease in most hematologic parameters after four-year follow-up. We found a positive association of benzene with the decline in monocyte counts and a negative association of toluene with the decline in MCHC. The associations of BTX components with the decline in hematologic parameters were mostly significantly stronger in subjects with higher baseline hematologic parameters, males, drinkers, and overweighted subjects. gWQS regression models found that BTX had combined effects on the decline in monocyte counts, RBC counts, and hemoglobin concentrations. These findings provided further evidence of complex hematological effects of long-term occupational exposure to BTX components. Finally, we estimated the BMD and BMDL for each BTX component to proposed some REL based on their hematological effects.

The most commonly-used exposure assessment methods in occupational population are external environment monitoring and internal exposure biomarker detection. However, BTX components and their metabolites in the biological fluids of exposed subjects have relatively short half-lives (Carrieri et al. 2006), which makes them less suitable for assessing long-term exposure levels. Although personal sampling is a more precise exposure assessment method, it is relatively difficult to be long-termly 
adopted in a cohort study with a relatively large sample size. Furthermore, Lee et al. (2006) have reported that there was no difference in BTX levels between personal and area sampling methods. With these theoretical and practical considerations, we chose area sampling method to measure long-term TWA concentrations for BTX components in workplaces of BEPWC participants. We found that the annual average TWA concentrations of all BTX components were relatively stable. Thus, we calculated the individual BTX CED levels based on long-term average TWA concentrations and work years. We also performed a pilot substudy and observed a significant correlation between the CED indices (represented by benzene CED levels) and commonly-used biomarkers (represented by urinary SPMA) in BEPWC cohort.

The present study found that most hematologic parameters were significantly decreased after four-year follow-up. The plausible mechanisms might be the cumulative exposure to hazard factors with hematotoxicity and the aging-related functional attrition of hematopoietic stem cells (HSCs). Petrochemical industry is a major source of multiple hazardous and toxic air pollution. Mounting evidence have linked increased risk of hematological malignancies, especially leukemia, with petrochemical industrial activities and residential petrochemical exposure (Jephcote et al. 2020; Lin et al. 2020;). Some cross-sectional studies have also explored the influences of petrochemical industry on early hematological effects, mainly reflected by the discordant differences of hematologic parameters in exposed individuals when compared to controls (Chen et al. 2019; Tsai et al. 2004). Khuder et al. (1999) conducted a small cohort study in 105 workers from a petroleum company, and observed all complete blood counts, except for WBC counts, were significantly decreased during the follow-up period. Our larger cohort study also observed some reduction in hematologic parameters, further highlighting the importance of monitoring hematologic parameters in health surveillance and protection for petrochemical workers. Furthermore, the chronological and biological age increased during the follow-up period. Hematopoiesis declines during aging, which emerges as the integrative consequence of multiple types of damage, such as decrease in cell cycle activity of HSCs, accumulation of DNA damages, telomere shortening, and increased levels of inflammatory signaling (Bousounis et al. 2021; López-Otín et al. 2013), The deregulation of HSC homeostasis may result in adverse hematological effects, such as an increased incidence of amenia and hematological malignancies (Bousounis et al. 2021; López-Otín et al. 2013). Our findings might provide further epidemiologic evidence of aging-related decline in hematopoiesis, manifested as decreased hematologic parameters. Intriguingly, we observed significant sex differences in the magnitude of declines in hematologic parameters. It is widely known that important biological and behavioral differences are existed between females and male, which affect the incidence, prognosis, and mortality of many widespread diseases, including hematological malignancies (BenBatalla et al. 2019).

Considering that BTX components are important toxic substances in the releases from petrochemical industry, we preliminarily explored their associations with the decline in hematologic parameters. We observed a positive association of benzene with the decline in monocyte counts and a negative association of toluene with the decline in MCHC. Benzene is the most hazardous and striking BTX compound which has been widely-recognized to induce hematotoxicity in humans for over 100 years (McHale et al. 2012). One representative manifestation of benzene-induced hematotoxicity is the 
reduction in all types of leukocytes (including monocytes), even in a low dose (<1ppm) (Lan et al. 2004; McHale et al. 2012). The present study had also found a positive association of long-term occupational benzene exposure with the decline in monocyte counts. However, the widely-reported relations of benzene with WBC counts were not found in this longitudinal analysis. This may be due to the relatively short follow-up period during which the effects of benzene might not yet be present. In additions to benzene, the influences of toluene on hematologic parameters have also drawn more and more attentions in recent years (Cakmak et al. 2020; Chen et al. 2019; Doherty et al. 2017). The cross-sectional studies conducted by Cakmak et al. (2020), Chen et al. (2019), and Doherty et al. (2017) have observed some significant but inconsistent associations of toluene with several hematologic parameters, such as hemoglobin concentrations and the counts of WBC, lymphocytes, RBC, and platelets. In the present study, we also found a negative association of benzene with the decline in $\mathrm{MCHC}$. The findings from the previous studies and our research collectively suggested that toluene may also have the potential to induce hematotoxicity. However, the existing evidences regarding its hematological effects are relatively limited and inconsistent (ATSDR 2017), and further investigations are warranted to look at the hematological effects of toluene in more depth and verify our findings.

Effect modification analysis showed that the associations of BTX exposure with the decline in hematologic parameters were mostly stronger in subjects with higher baseline parameters. Two metaanalyses of randomized clinical trials have also observed some similar findings (Brunström and Carlberg 2018; Navarese et al. 2018). Brunström and Carlberg (2018) found that treatment to lower blood pressure was associated with a reduced risk for death and cardiovascular disease when baseline systolic blood pressure $\geq 140 \mathrm{~mm} \mathrm{Hg}$, while the treatment effect was limited when baseline systolic blood pressure < $140 \mathrm{~mm}$ Hg. Similarly, Navarese et al. (2018) also observed that LDL-C lowering therapy was associated with a reduced total mortality with higher baseline LDL-C levels, while this relationship was not present with lower baseline LDL-C. These findings from the previous studies and our study suggested that subjects with higher baseline levels might be more sensitive to the effects of external factors (including toxic substances and drugs), while those with lower baseline values might be less likely to experience any further decreases, probably due to homeostasis mechanisms. We also found that the association of BTX exposure with the decline in hematologic parameters were mostly stronger in males. Worldwide data have shown that compared with females, males are both at increased risk and have a poorer prognosis for leukemia (Ben-Batalla et al. 2019). Our findings further proved that males might be more predisposed to BTX-associated hematotoxicity. The possible causes for these phenomena include differences in other environmental exposures, lifestyle, endogenous hormones, sex chromosomes, epigenetics, and the complex multidirectional interactions between these factors (Ben-Batalla et al. 2019). Besides, Wang et al. (2021) found that under the same environmental exposure, the benzene metabolites in females' urine were higher than males, which may be due to the higher biotransformation ability and faster detoxification of benzene in females than males. Furthermore, the present study also observed stronger associations of BTX exposure with the decline in hematologic parameters in overweighted subjects with $\mathrm{BMI} \geq 24 \mathrm{~kg} / \mathrm{m}^{2}$. Due to their lipophilicity, BTX components mainly accumulate in the fat-enriched tissues. Therefore, fat content in the body might affect the distribution, metabolism, and eventually the toxicity of 
BTX components (Zhang et al. 2020). Taken together, these results of effect modification analysis provided some clues that can be used for more detailed risk assessment. However, further researches are needed to verify our findings of effect modification and determine the underlying mechanisms.

In addition, we used gWQS regression to model the associations of a mix of three BTX components with the decline in hematologic parameters. We revealed that benzene, toluene, and xylene had combined effects on the decline in monocyte counts, RBC counts, and hemoglobin concentrations, further providing some new epidemiological evidence of the existence of complex joint toxic actions among BTX components in producing hematotoxicity. The joint toxic actions among BTX components are of great concern for a long time (ATSDR 2004). For instance, high amounts of toluene have been shown to inhibit benzene metabolism and subsequent myelotoxicity (Andrews et al. 1977), while lower concentrations of toluene have been suggested to enhance benzene genotoxicity and confounded its effects on many metabolic enzymes and blood cell populations (Bird et al. 2010; Robert Schnatter et al. 2010). Competitive metabolic interactions are believed to be the most plausible mechanism of BTX combined effects, as they are all known substrates for CYP2E1 (ATSDR 2004). The effect of CYP2E1 induction of one BTX component might be masked by other competing substrate(s) at higher co-exposures, but at lower co-exposures the induction provides for more BTX components to be metabolized to toxic metabolites (Bird et al. 2010). Complex combined effects among BTX components on the decline in hematologic parameters were also observed in the BEPWC participants who had been co-exposed to lower concentrations of BTX components. Although the underlying mechanisms are still not quite clear, our study further pointed to the need to scrutinize levels of all BTX compounds in the occupational environment and consider their co-exposure effects in the risk assessment.

Exposure standards are developed to protect the public and the employee from toxic health effects of harmful substances and activities. One of the most crucial processes in exposure standard setting is dose-response relationship assessment which provides the technical information on which to base the setting of standards for "safe" exposure. Recently, BMD estimation method is widely accepted by regulatory agencies and scientific community to determine the "point of departure" (POD) for a specific dose-response relationship and derive human health guidance values (Qing et al. 2021). We also used BMD method in the present study to propose some REL for BTX components based on their hematological effects. Determination of endpoints is the first step for BMD calculations. However, there are currently no unified widely-acknowledged definitions for hematological damage. Many studies, including the present study, have evaluated the associations of BTX components and hematologic parameters, but they have reported many inconsistent results, even for benzene (ATSDR 2007a, b, 2017). Given the complex and inconsistent findings for the hematological effects of BTX components, it might be very hard for us to decide which hematologic parameter should be selected to define hematological damage. Furthermore, using only one parameter (such as WBC counts) to define hematological damage might exclude the endpoints with the potential of having the most sensitive effect for risk assessment applications from the BMD analysis (EPA 2012). Thus, it might be more appropriate to define hematological damage based on a serial of the hematologic parameters, not only one parameter. In the present study, we selected night hematologic parameters which have clinical relevance to chronic 
exposure to toxic chemicals and bone marrow problems as the parameters of primary interest. In order to increase the specificity and reduce the false positive rate, only the subjects with at least two "abnormal" parameters were classified as the cases of hematological damage. Furthermore, in order to increase the sensitivity, we defined hematological damage not only according to the hematologic parameter levels detected in follow-up stage, but also based on their four-year decline. We considered it as "abnormal" if the levels of at least two selected parameters (except for MPV which has no related national standards) in follow-up stage were below the lower limits (not both lower and upper limits) of normal range in Chinese adults. We also considered it as "abnormal" if the magnitude of the decline in at least two selected parameters higher than the upper $5 \%$ percentile in population of the same sex (not in the total population). The main reasons were as follows. Firstly, it is commonly believed that BTX components, especially benzene, are associated with decreased numbers of blood cell types (ATSDR 2007a, b, 2017). Secondly, the results in the present study, although many of which were insignificant after FDR adjustment, also suggested that BTX components might be positively associated with the four-year decline in most hematologic parameters. Furthermore, the magnitude of decline in parameters and their associations with BTX components showed significant sex differences in the present study.

Based on the calculated BMDL and up to 40 years of working duration, we proposed REL-TWA for benzene, toluene, and xylene as $0.0390 \mathrm{mg} / \mathrm{m}^{3}$ (about $0.0125 \mathrm{ppm}$ ), $0.0331 \mathrm{mg} / \mathrm{m}^{3}$ (about $0.0088 \mathrm{ppm}$ ), and $0.0578 \mathrm{mg} / \mathrm{m}^{3}$ (about $0.0122 \mathrm{ppm}$ ), respectively. These REL-TWA proposed in the present study were much lower the current regulatory or advisory exposure limits, such as Permissible Exposure Limits-TWA (PEL-TWA) established by U.S. Occupational Safety and Health Administration (OSHA), Permissible Concentrations-TWA (PC-TWA) in China, Threshold Limit Values-TWA (TLV-TWA) recommended by American Conference of Governmental and Industrial Hygienists (ACGIH), and RfC established by EPA. Zhang et al. (2016) also estimated BMD based on only WBC counts in benzene-exposed workers of shoe factories. With BMR levels at 0.1 in the risk of reduced WBC counts, the BMDL for benzene CED levels was calculated as $1.37 \mathrm{ppm} \times y e a r$ (about $4.37 \mathrm{mg} / \mathrm{m}^{3} \times y e a r$ ) (Zhang et al. 2016), which was a little higher than our estimated BMDL $\left(1.559 \mathrm{mg} / \mathrm{m}^{3} \times y e a r\right)$. These differences might be due to the different definition of hematological damages. However, as the BMD models couldn't include covariates, the results of BMD estimation would be vulnerable to confounding bias which may limit the modeling of human data to some extent (EPA 2012). Furthermore, considering that the exposure standards are mostly determined by a trade-off or balancing of the assessed risks and costs of reducing exposure levels, further researches are needed to verify our findings and assess the availability of these REL-TWA of BTX components estimated in the present cohort study.

The present study had several major strengths. First, our participants were petrochemical workers who had been regularly exposed to BTX-rich emissions for more than one year, with their occupational BTX source and levels showing little fluctuation. Thus, we calculated BTX CED levels to evaluate their longterm exposure doses, rather than the internal exposure biomarkers which may reflect recent exposure. Secondly, we used BMD estimation method to propose REL based on some reasonable and comprehensive criteria of hematological damage. However, some limitations in the present study should 
also be noted. Firstly, in order to eliminate the influences of baseline health status on our results, we intentionally selected the BEPWC participants from workers without any serious diseases or any obviously abnormities in baseline physical examination. Furthermore, these participants had been exposed to BTX components for, on average, 18.75 years prior to the baseline stage. Thus, it was likely to result in healthy worker selection and survivor effects that might bias our results. Secondly, the present study was conducted in an occupational population, and it is uncertain whether our findings could be extrapolated to the general population. Moreover, although our BEPWC participants were intentionally selected from the workplaces where BTX compounds were always the primary occupational hazards, they may be also co-exposed to other hazards in their working and living environments which may also cause hematotoxicity. Despite we had adjusted factory location and main lifestyle factors (such as smoking and drinking status) in the statistical analysis to control their confounding effects as a whole, further studies are still warranted to evaluate their influences on our results.

\section{Conclusions}

We established BEPWC cohort and observed a significant decrease in most hematologic parameters after four-year follow-up, further highlighting the importance of monitoring hematologic parameters in health surveillance and protection for petrochemical workers. We also found significant associations and combined effects of BTX components with the decline in some hematologic parameters, providing further perspective evidence of complex hematological effects of long-term occupational exposure to BTX components. Finally, we estimated the BMD and BMDL for BTX components to propose some REL based on their hematological effects. Further investigations are warranted to verify our findings, determine the underlying mechanisms, and assess the availability of the REL-TWA of BTX components estimated in the present study.

\section{Abbreviations}

BTX, Benzene, toluene, and xylenes, CYPs, cytochrome P450 enzymes, IARC, International Agency for Research on Cancer, RBC, red blood cell, EPA, Environmental Protection Agency, RfC, Reference Concentrations, ATSDR, Agency for Toxic Substances and Disease Registry, MRL, minimal risk level, REL, reference exposure level, NOAEL, no-observed-adverse-effect level, LOAEL, lowest-observed-adverse-effect levels, BMD, benchmark doses, BMR, benchmark response, BMDL, BMD's statistical lower confidence limit, BEPWC, BTX-Exposed Petrochemical workers Cohort, CED, cumulative exposure doses, 8h-TWA, 8hour time-weighted average concentrations, SPMA, S-phenylmercapturic acid, NIOSH, National Institute for Occupational Safety and Health, LOD, limits of detection, WBC, white blood cell, MCV, mean corpuscular volume, $\mathrm{MCHC}$, mean corpuscular hemoglobin concentration, $\mathrm{MCH}$, mean corpuscular hemoglobin, MPV, mean platelet volume, PDW, platelet distribution width, SD, standard deviation, Intransformed, natural logarithm transformed, BMI, body mass index, FDR, false discovery rate, gWQS, generalized weighted quantile sum regression, BMDS, Benchmark Dose Software, AIC, Akaike's Information Criterion, HSCs, hematopoietic stem cells, POD, point of departure, PEL-TWA, Permissible 
Exposure Limits-TWA, OSHA, Occupational Safety and Health Administration, PC-TWA, Permissible Concentrations-TWA, TLV-TWA, Threshold Limit Values-TWA, ACGIH, American Conference of Governmental and Industrial Hygienists.

\section{Declarations}

Ethics approval and consent to participate: The present study was approved by the Ethical Review Committee of School of Public Health, Sun Yat-sen University. Each participant in the present study have signed a written informed consent form before the study.

Consent for publication: Not applicable.

Availability of data and materials: The datasets generated and/or analyzed during the present study are not publicly available but are available from the corresponding author on reasonable request.

Competing interests: The authors declare that they have no competing interests.

Funding: The study was funded by the Natural National Scientific Foundation of China [grant numbers: 81973006, 81973076, and 81402658], Guangdong Basic and Applied Basic Research Foundation [grant number: 2020A1515010753], Science and Technology Planning Project of Guangzhou [grant number: 202002030281], and the Young Teachers Training Program of Sun Yat-sen University [grant number: 18ykpy14].

Authors' contributions: $Z Z, X L$, and QD wrote the draft paper, QD and $Y X$ revised the manuscript and improved the language, $Z Z, X L, X Z, Y Y Z, N D$, and $Q D$ analyzed the data, $X X, Y X$, and $Q D$ designed the study, GL, AY, YH, SD, YZ, and $Y X$ contributed to data collection, $Z Z, X Z, X X, Y X$, and $Q D$ contributions to the progress of the study, and all authors have approved the final article.

Acknowledgements: We thank all study participants, research staffs, and students who participated in this work.

\section{References}

1. Andrews LS, Lee EW, Witmer CM, Kocsis JJ, Snyder R. Effects of toluene on the metabolism, disposition and hemopoietic toxicity of [3H]benzene. Biochem Pharmacol, 1977,26:293-300.

2. ATSDR. Interaction profile for benzene, toluene, ethylbenzene, and xylenes (BTEX). US Department of Health and Human Services, Agency for Toxic Substances and Disease Registry, USA. 2004.

3. ATSDR. Toxicological profile for xylene. US Department of Health and Human Services, Agency for Toxic Substances and Disease Registry, USA. 2007a.

4. ATSDR. Toxicological profile for benzene. US Department of Health and Human Services, Agency for Toxic Substances and Disease Registry, USA. 2007b. 
5. ATSDR. Toxicological profile for toluene. US Department of Health and Human Services, Agency for Toxic Substances and Disease Registry, USA. 2017.

6. Ben-Batalla I, Vargas-Delgado ME, Meier L, Loges S. Sexual dimorphism in solid and hematological malignancies. Semin Immunopathol. 2019,41: 251-263.

7. Bird MG, Wetmore BA, Letinski DJ, Nicolich M, Chen M, Schnatter AR, et al. Influence of toluene coexposure on the metabolism and genotoxicity of benzene in mice using continuous and intermittent exposures. Chem Biol Interact. 2010,184:233-239.

8. Bolden AL, Kwiatkowski CF, Colborn T. New look at BTEX: are ambient levels a problem? Environ Sci Technol. 2015,49:5261-5276,.

9. Bousounis P, Bergo V, Trompouki E. Inflammation, aging and hematopoiesis: a complex relationship. Cells. 2021,10:1386.

10. Brunström M, Carlberg B. Association of blood pressure lowering with mortality and cardiovascular disease across blood pressure levels: a systematic review and meta-analysis. JAMA Intern Med. 2018,178:28-36.

11. Cakmak S, Cole C, Hebbern C, Andrade J, Dales R. Associations between blood volatile organic compounds, and changes in hematologic and biochemical profiles, in a population-based study. Environ Int. 2020,145:106121.

12. Carrieri M, Bonfiglio E, Scapellato ML, Macca I, Tranfo G, Faranda P, et al. Comparison of exposure assessment methods in occupational exposure to benzene in gasoline filling-station attendants. Toxicol Lett. 2006,162:146-152.

13. Cetin E, Odabasi M, Seyfioglu R. Ambient volatile organic compound (VOC) concentrations around a petrochemical complex and a petroleum refinery. Sci Total Environ. 2003,312:103-112.

14. Chen Q, Sun H, Zhang J, Xu Y, Ding Z. The hematologic effects of BTEX exposure among elderly residents in Nanjing: a cross-sectional study. Environ Sci Pollut Res Int. 2019,26:10552-10561.

15. Czarnota J, Gennings C, Colt JS, De Roos AJ, Cerhan JR, Severson RK, et al. Analysis of Environmental Chemical Mixtures and Non-Hodgkin Lymphoma Risk in the NCI-SEER NHL Study. Environ Health Persp. 2015,123:965-970.

16. Davidson CJ, Hannigan JH, Bowen SE. Effects of inhaled combined Benzene, Toluene, Ethylbenzene, and Xylenes (BTEX): Toward an environmental exposure model. Environ Toxicol Pharmacol. 2020,81:103518.

17. Deng Q, Dai X, Feng W, Huang S, Yuan Y, Xiao Y, et al. Co-exposure to metals and polycyclic aromatic hydrocarbons, microRNA expression, and early health damage in coke oven workers. Environ Int. 2019,122:369-380.

18. Doherty BT, Kwok RK, Curry MD, Ekenga C, Chambers D, Sandler DP, et al. Associations between blood BTEXS concentrations and hematologic parameters among adult residents of the U.S. Gulf States. Environ Res. 2017,156:579-587.

19. EPA. Integrated risk information system (IRIS) on toluene. National Center for Environmental Assessment, Office of Research and Development, Washington, DC. 2005. 
20. EPA. Benchmark dose technical guidance. United States Environmental Protection Agency, Washington, DC. 2012.

21. Jephcote C, Brown D, Verbeek T, Mah A. A systematic review and meta-analysis of haematological malignancies in residents living near petrochemical facilities. Environ Health. 2020,19:53.

22. Khuder SA, Youngdale MC, Bisesi MS, Schaub EA. Assessment of complete blood count variations among workers exposed to low levels of benzene. J Occup Environ Med. 1999,41:821-826.

23. Kim MK, Han K, Park YM, Kwon HS, Kang G, Yoon KH, et al. Associations of variability in blood pressure, glucose and cholesterol concentrations, and body mass index with mortality and cardiovascular outcomes in the general population. Circulation. 2018,138:2627-2637.

24. Koh DH, Jeon HK, Lee SG, Ryu HW. The relationship between low-level benzene exposure and blood cell counts in Korean workers. Occup Environ Med. 2015,72:421-427.

25. Lan Q, Zhang L, Li G, Vermeulen R, Weinberg RS, Dosemeci M, et al. Hematotoxicity in workers exposed to low levels of benzene. Science. 2004,306:1774-1776.

26. Lee CW, Dai YT, Chien CH, Hsu DJ. Characteristics and health impacts of volatile organic compounds in photocopy centers. Environ Res. 2006,100:139-149.

27. Lin CK, Hsu YT, Brown KD, Pokharel B, Wei Y, Chen ST. Residential exposure to petrochemical industrial complexes and the risk of leukemia: A systematic review and exposure-response metaanalysis. Environ Pollut. 2020,258:113476.

28. López-Otín C, Blasco MA, Partridge L, Serrano M, Kroemer G. The hallmarks of aging. Cell. 2013,153:1194-1217.

29. McHale CM, Zhang L, Smith MT. Current understanding of the mechanism of benzene-induced leukemia in humans: implications for risk assessment. Carcinogenesis. 2012,33:240-252.

30. Navarese EP, Robinson JG, Kowalewski M, Kolodziejczak M, Andreotti F, Bliden K, et al. Association between baseline LDL-C level and total and cardiovascular mortality after LDL-C lowering: a systematic review and meta-analysis. JAMA. 2018,319:1566-1579.

31. Pike, N. Using false discovery rates for multiple comparisons in ecology and evolution. Methods Ecol Evol. 2011,2:278-282.

32. Qing Y, Yang JQ, Zhu YS, Li YZ, Zheng WW, Wu M, et al. Dose-response evaluation of urinary cadmium and kidney injury biomarkers in Chinese residents and dietary limit standards. Environmental Health. 2021,20,

33. Qu Q, Shore R, Li G, Jin X, Chen LC, Cohen B, et al. Hematological changes among Chinese workers with a broad range of benzene exposures. Am J Ind Med. 2002,42:275-285.

34. Robert Schnatter A, Kerzic PJ, Zhou Y, Chen M, Nicolich MJ, Lavelle K, et al.. Peripheral blood effects in benzene-exposed workers. Chem Biol Interact. 2010,184:174-181.

35. Samadi MT, Shakerkhatibi M, Poorolajal J, Rahmani A, Rafieemehr H, Hesam M. Association of long term exposure to outdoor volatile organic compounds (BTXS) with pro-inflammatory biomarkers and 
hematologic parameters in urban adults: A cross-sectional study in Tabriz, Iran. Ecotoxicol Environ Saf. 2019,180:152-159.

36. Tsai SP, Fox EE, Ransdell JD, Wendt JK, Waddell LC, Donnelly RP. A hematology surveillance study of petrochemical workers exposed to benzene. Regul Toxicol Pharmacol. 2004,40:67-73.

37. Tuakuila J. S-phenylmercapturic acid (S-PMA) levels in urine as an indicator of exposure to benzene in the Kinshasa population. Int J Hyg Environ Health. 2013,216:494-498.

38. Wang B, Han L, Wang K, Zhou Y, Pu Y, Zhang J, et al. Gender differences in hematotoxicity of benzene-exposed workers, three cross-sectional studies on 218,061 subjects. Environ Sci Pollut Res Int. 2021,28: 57297-57307.

39. Zhang GH, Ji BQ, Li Y, Zheng GQ, Ye LL, Hao YH, et al. Benchmark doses based on abnormality of WBC or micronucleus frequency in benzene-exposed Chinese workers. J Occup Environ Med. 2016,58:e39-44.

40. Zhang X, Deng Q, He Z, Li J, Ma X, Zhang Z, et al. Influence of benzene exposure, fat content, and their interactions on erythroid-related hematologic parameters in petrochemical workers: a crosssectional study. BMC Public Health. 2020,20:382.

\section{Supplementary Files}

This is a list of supplementary files associated with this preprint. Click to download.

- Additionalfile1.docx 